\title{
Pre-Pregnancy Risk Factors for Intrauterine Fetal Mortality in Ghana
}

\author{
Albert Luguterah", ${ }^{1, *}$ Kaku Sagary Nokoe ${ }^{2}$ \\ ${ }^{1}$ Department of Statistics, University for Development Studies, Navrongo, Ghana \\ ${ }^{2}$ Department of Mathematics, University of Energy \& Natural Resources, Sunyani, Ghana \\ *Corresponding author: adlugu@yahoo.com
}

Received May 14, 2013; Revised May 26, 2013; Accepted May 29, 2013

\begin{abstract}
Fetal mortality refers to the intrauterine death of a fetus and is a major, but often overlooked public health issue in Ghana. Due in part to a paucity of knowledge of the incidence, etiology and prevention strategies, much of the public concern on reproductive loss has focused on infant mortality. Effective antenatal care, which must be evidence-based information driven, necessitates regular, updated and reviewed studies on risk factors associated with fetal mortality to help in addressing this phenomenon. In this study, using data of the 2007 Ghana Maternal Health Survey, the incidence and some pre-pregnancy risk factors of fetal mortality were studied using non-parametric procedures. The results showed that the first trimester of pregnancy was the riskiest period, accounting for over $50 \%$ of all fetal mortalities in Ghana: The third month, where over $5 \%$ of pregnancies are lost, is the riskiest month of pregnancy. Previous pregnancy outcomes, the age and education of the mother as well as her place of residence, were shown to be significantly associated with fetal mortality at the $5 \%$ significance level: Particularly, women with a history of abortion and those who have never given birth are over 4 times more likely to lose their pregnancy than their counterparts. The results highlight the adverse effects of the pressures of urban life on fetal survival, as well as the need for early antenatal care and comprehensive care for women who lose a fetus.
\end{abstract}

Keywords: fetal mortality, intrauterine, bad obstetric history, first trimester, risk, fetal survival

\section{Introduction}

The death of a baby is one of the most painful things that can happen to a family [1]. Most women are anxious and nervous and may swell with pleasure and delight when they are tested positive for pregnancy. Being pregnant creates a lot of expectations in the minds of most families and the loss of such a pregnancy represents more than the loss of a fetus. Pregnancy loss can be very devastating, sometimes coming with emotional, psychological, medical and other consequences on the woman, couple, family and even society. Studies have shown that the loss of a pregnancy is associated with an increased risk of losing one's relationship [2], and for women younger than 35 years, consequently developing atherosclerosis [3,4].

Fetal mortality refers to the intrauterine death of a fetus and is a major, but overlooked public health issue. Partly due to paucity of knowledge of the incidence, etiology and prevention strategies, much of the public concern on reproductive loss has focused on infant mortality [5]. Pregnant women lose their babies through such means as abortions, stillbirths, etc. The National Center for Health Statistics estimates that there are over 1 million fetal losses per year in the United States with a vast majority of them in the first 20 weeks of gestation [6]. Fetal mortality in the United States in 2006, was shown to differ by maternal age, marital status, race, Hispanic origin and
State of residence [5]. Several other risk factors have been associated with fetal mortality including maternal obesity, smoking or drinking during pregnancy, severe or uncontrolled hypertension or diabetes, intrauterine growth retardation, congenital anomalies, infections, placental and cord problems, and previous pregnancy outcomes [7-15]. Antenatal care is one major way of dealing with this public health issue.

According to the report of the National Collaborating Centre for Women's and Children's Health (NCC-WCH) and published by the Royal college of Obstetrics and Gynecologists [16], good antenatal care needs to be evidence-based information driven. With increasing interest in the study of reproductive losses before birth in recent times, many studies have been made; but not in Africa or Ghana in particular. The question then is what is the situation of intrauterine fetal mortality in Ghana? And what are the associated risk factors? This study therefore focused on the incidence of fetal mortality in Ghana and the identification and quantification of relative risk of some pre-pregnancy risk factors associated with this phenomenon. Using data of the 2007 Ghana Maternal Health Survey and Non Parametric survival analysis techniques, this study provides insight into the kind of segments of the population that is at high risk of losing a pregnancy in Ghana and is intended to aid proper, information driven and up to date antenatal care.

\section{Materials and Methods}




\subsection{Data Set}

The study was a retrospective cohort study covering all conceptions between 2002 and 2007 among the selected women in Ghana. Every pregnancy was thus followed from conception to death of foetus, or live birth, or date on which data was collected; whichever came first.

The data for this study was obtained from the Ghana statistical Service and was collected in the Ghana Maternal health survey 2007. The Survey was the first nationally representative population based survey to collect information on maternal health and mortality in Ghana [17] and was jointly implemented by the Ghana Statistical Service and the Ghana Health Service with technical assistance from the Macro International, a U.S.A based company.

The data was collected through the multi phase approach. In phase one, 1600 clusters were selected from the 10 administrative regions of Ghana and across the urban and rural areas. The clusters were wards and subwards drawn from the 2000 population census with the sample size estimated from information in the 2003 Ghana demographic and health survey; each cluster was expected to yield on average, 150 households. A questionnaire was administered to 227,715 households from the 1600 clusters, to obtain information on all deaths in the households especially maternal deaths: In phase two, information was collected on a wide range of maternal health issues pertaining to pregnancies, live births, abortions and miscarriages, utilization of health services in relation to these events as well as the sibling history from 10,370 women aged 15-49 years, selected from 10,858 households, obtained from 400 nationally representative clusters stratified by region and urban-rural residence. Institutional populations and household residing in refugee camps were excluded [17].

Survival analysis typically follows a group of people from beginning to the end of a study to observe when each member of the group will fail: This cohort is known as a stationary cohort. However, in this study, the moving or cross sectional cohort, which uses observations over a single cross section of time, is used and manipulated to represent a cohort. By this technique, different individuals may have different start points within the selected study time frame however the estimates derived provide estimates of current trends in survival. The time frame used in this study is 2002 to 2007 and all reported pregnancies within this period were therefore considered for this study.

Variables used for estimating survivorship were time to death, for the dead, and period of observation for those alive. These data are however classified as censored (for those not dead) and uncensored (for those dead). For fetal survival, these variables were defined as the duration of the pregnancy and was classified as uncensored for failed pregnancies and censored if the pregnancy was still alive at the time the data was collected or had lead to a successful delivery: It was measured in months. All censored data are right censored. In all, a total sample of 9083 pregnancies, out of which 1,652 (18.2\%) had failed, with the rest being right censored, formed the basis of this study.

The pre-pregnancy risk factors of the woman assessed in this study, at the individual and joint level, included her location of residence, religion and age, as well as whether she had ever been to school, ever had an abortion (both for induced and spontaneous), as well as ever delivered a baby, still or live. Three Regions, Greater Accra, Eastern and Ashanti Regions, that received some interventions to reduce maternal mortality and morbidity in 2006 (defined as the R3M Regions) were also of interest.

From the sample of 9083, 5513 were resident in rural communities, 499 had never given birth while 1948 had aborted before. Six thousand one hundred and ninety-eight (6198) of the respondents had ever been to school. Seventy-eight percent (7104) were below 36 years of age.

\subsection{Methods}

The challenge arising from the presence of censored observations, having at most one event occurring per subject, and times being highly skewed, make the use of standard statistical techniques, usually based on the normality assumptions, inappropriate. The use of non parametric survival techniques is advantageous because it does not make any assumption of the distribution, and uses a lot more information in developing the estimates as compared to other methods.

To estimate the survival function $S(t)$, we assumed that fetal survival are a probabilistic or stochastic process i.e. the times at which the deaths of fetus occur are an outcome of some random process. The time to death for any fetus, $T$, is therefore a random variable having a probability distribution $f(t)$ and consequently a cumulative distribution function $F(t)$ was determined from which the hazard function $h(t)$ was found.

\subsubsection{Estimating the Survival Functions}

In this study we used the Life table method, to estimate the survival functions. The Life table method, which estimates the survival functions for each interval, uses the mid points of the intervals to estimate the hazard and density functions, and the upper limit to estimate survival functions [18].

Their standard errors were estimated using methods proposed by Gehan [18] and Greenwood [19].

\subsubsection{Log rank Test}

Furthermore, the Log-rank test [20], which is a suitable non parametric test of difference for survival functions, for data with some censored values, was used to test for differences in survival function among the levels, and for each of the selected pre-pregnancy risk factors. For a factor with $k$ levels, this tests the hypothesis that;

$$
H_{0}: S_{1}(t)=S_{2}(t)=\cdots=S_{k}(t) \text { for all } t \text {. }
$$

Against the alternative;

$$
H_{2} \text { : not all } S_{j}(t) \text { are equal, } j=1,2, \ldots, k \text {. }
$$

where $S_{j}(t)$ is the survival function for the $j^{\text {th }}$ group.

This is tested as a chi-square test which compares the observed numbers of failures to the expected number of failure under the hypothesis. A large chi-square value will lead to a rejection of the null hypothesis in favor of the alternative that the $k$ levels do not have the same survival distribution.

\subsubsection{Proportional Hazard Regression}


Since survival time usually violates the normality assumption, the Cox proportional regression as proposed by Cox [21] was used to determine the effect of some prepregnancy risk factors on fetal hazard and hence survival. In this model, the hazard for an individual was assumed to be related to the covariates through the equation;

$$
h_{i}(t)=\lambda_{0}(t) \exp \left\{\beta_{1} x_{i 1}+\cdots+\beta_{k} x_{i k}\right\}
$$

The ratio of the hazard for two individuals $i$ and $j$ (say rural women and urban women) is then given by;

$$
\frac{h_{i}(t)}{h_{j}(t)}=\exp \left\{\beta_{1}\left(x_{i 1}-x_{j 1}\right)+\cdots+\beta_{k}\left(x_{i k}-x_{j k}\right)\right\}
$$

The exponent of $\beta_{1}, \ldots, \beta_{k}$ measured the relative risk for the $i^{\text {th }}$ child, over the $j^{\text {th }}$ with respect to the change in the $x_{i}^{\text {th }}$ covariate, $l=1, \ldots, k$ respectively.

\section{Results}

Table 1 shows the hazard, density and survival estimates for a pregnancy at each of the specified time points. About $17 \%$ of conceptions (Survival of 0.826137 ) are lost before birth: $9 \%$ of them in the first trimester, $6.5 \%$ and $1.5 \%$ in the second and third trimesters respectively. The instantaneous risk of losing a child at each time point is given by the hazard estimates in Table 1. The third month is the riskiest month of pregnancy as over $5 \%$ of the pregnancies in this month fail (hazard=0.0538352). Figure 1 shows this risk to be increasing in the first three months, followed by a sharp decrease and then gradual decrease till birth.

All the factors tested are shown to significantly affect the survival of a fetus as shown in the results of the log rank test (Table 2). Differences among the 10 regions of Ghana were observed. Apart from the Eastern Region, Regions that had received some interventions in the past seemed not to be at lower risk than the western region.

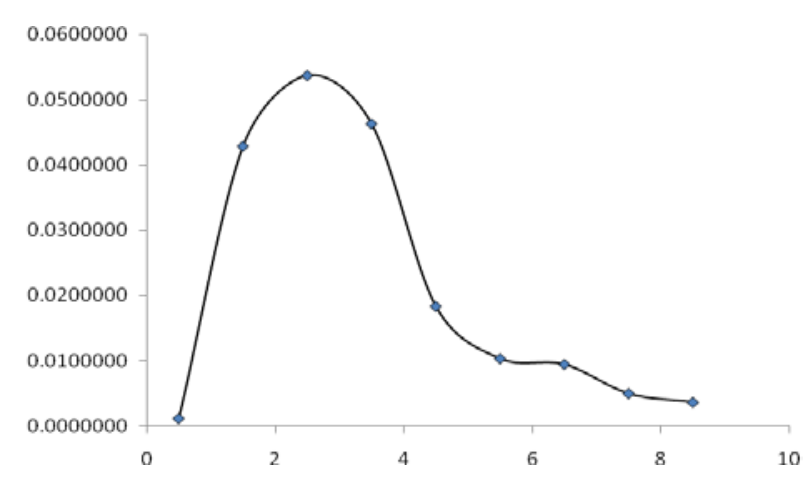

Figure 1. Hazard Plot for Fetal Survival

Table 1. Hazard, Density and Survival Estimates of Fetal

\begin{tabular}{cccccccc}
\hline Time & Hazard & Std error & Density & Std error & Time & Survival & Std error \\
\hline 0.5 & 0.0011016 & 0.0003483 & 0.001101 & 0.000348 & 1 & 0.998899 \\
1.5 & 0.0429659 & 0.0022007 & 0.042016 & 0.002107 & 2 & 0.956883 \\
2.5 & 0.0538352 & 0.0025313 & 0.050164 & 0.002300 & 3 & 0.906719 \\
3.5 & 0.0463970 & 0.0024213 & 0.041115 & 0.002102 & 4 & 0.002133 \\
4.5 & 0.0183632 & 0.0015575 & 0.015751 & 0.001325 & 5 & 0.849854 \\
5.5 & 0.0103128 & 0.0011829 & 0.008719 & 0.000996 & 0.003596 & 0.003770 \\
6.5 & 0.0094353 & 0.0011442 & 0.007899 & 0.000954 & 6 & 0.841134 \\
7.5 & 0.0049558 & 0.0008377 & 0.004119 & 0.000695 & 0.003862 & 0.833235 \\
8.5 & 0.0035995 & 0.0007199 & 0.002979 & 0.000595 & 8 & 0.829116 \\
\hline \hline
\end{tabular}

\begin{tabular}{|c|c|c|c|}
\hline Variable & d.f & Chi-Square & P-Value \\
\hline Region & 9 & 261.475 & $0.000^{*}$ \\
\hline Rural/Urban & 1 & 243.776 & $0.000^{*}$ \\
\hline Woman ever schooled & 1 & 201.121 & $0.000 *$ \\
\hline Woman's religion & 3 & 129.070 & $0.000^{*}$ \\
\hline Woman's Age (Categorized) & 3 & 27.686 & $0.000 *$ \\
\hline Woman ever had an induced abortion & 1 & 1677.600 & $0.000 *$ \\
\hline Woman ever had a spontaneous abortion & 1 & 1361.820 & $0.000 *$ \\
\hline Woman ever had a Still birth & 1 & 151.930 & $0.000 *$ \\
\hline Woman ever delivered a live baby & 1 & 1336.850 & $0.000 *$ \\
\hline
\end{tabular}

Table 2. Log Rank Test of Some Prognostic Factors of Fetal Survival

*: Means significant at the 5\% significance level

d.f. Means degree of freedom 
Table 3. Cox Regression of Fetal Survival

\begin{tabular}{|c|c|c|c|c|c|c|}
\hline Characteristics of the Woman & Level & SE & Wald & d.f & P-Value & $\operatorname{Exp}(B)$ \\
\hline Rural Urban & Rural & 0.058 & 5.085 & 1 & $0.024 *$ & 0.877 \\
\hline Ever Attended School & No & 0.075 & 5.615 & 1 & $0.018^{*}$ & 0.837 \\
\hline \multirow[t]{10}{*}{ Region of Residence (compared with Western) } & & & 29.492 & 9 & $0.001^{*}$ & \\
\hline & Ashanti Region & 0.100 & 2.992 & 1 & 0.084 & 0.841 \\
\hline & Brong Ahafo Region & 0.118 & 3.406 & 1 & 0.065 & 0.805 \\
\hline & Central Region & 0.119 & 1.157 & 1 & 0.282 & 1.136 \\
\hline & Eastern Region & 0.104 & 4.204 & 1 & $0.040^{*}$ & 0.807 \\
\hline & Greater Accra Region & 0.103 & 0.114 & 1 & 0.735 & 1.035 \\
\hline & Northern Region & 0.152 & 3.640 & 1 & 0.056 & 0.748 \\
\hline & Upper East Region & 0.262 & 6.932 & 1 & $0.008^{*}$ & 0.502 \\
\hline & Upper West Region & 0.202 & 0.238 & 1 & 0.626 & 0.906 \\
\hline & Volta region & 0.126 & 0.166 & 1 & 0.684 & 0.950 \\
\hline \multirow[t]{4}{*}{ Religion (Compared with Traditionalist/Spiritualist) } & & & 1.226 & 3 & 0.747 & \\
\hline & Christian & 0.190 & 0.239 & 1 & 0.625 & 1.097 \\
\hline & Moslem & 0.199 & 0.112 & 1 & 0.738 & 1.069 \\
\hline & Others & 0.228 & 0.042 & 1 & 0.837 & 0.954 \\
\hline \multirow[t]{4}{*}{ Age (Compared with above 45 years) } & & & 26.567 & 3 & $0.000 *$ & \\
\hline & Below 26 years & 0.169 & 1.059 & 1 & 0.303 & 0.840 \\
\hline & 26 to 35 years & 0.167 & 6.506 & 1 & $0.011^{*}$ & 0.654 \\
\hline & 36 to 45 years & 0.171 & 7.027 & 1 & $0.008^{*}$ & 0.635 \\
\hline Woman ever delivered a live baby & No & 0.069 & 451.219 & 1 & $0.000 *$ & 4.307 \\
\hline Woman ever had spontaneous Abortion & No & 0.051 & 862.006 & 1 & $0.000 *$ & 0.224 \\
\hline Woman ever had induced Abortion & No & 0.054 & 795.180 & 1 & $0.000 *$ & 0.219 \\
\hline Woman ever had a Stillbirth & No & 0.074 & 129.919 & 1 & $0.000 *$ & 0.432 \\
\hline
\end{tabular}

*: and d.f Mean significant at the 5\% significance level and degree of freedom respectively

The significance and the relative risks of the various levels of the factors considered on the risk of losing a child, and hence its survival, are shown in the results of the Cox regression (Table 3). It may be observed that the risk of losing a fetus is significantly lower for rural dwellers (about $12.7 \%$ lower) than for urban dwellers. Women who have ever had a spontaneous or induced abortion, or never delivered a live baby have significantly higher (more than 4 times) higher risk of losing their fetus than women who have never experienced these mishaps. Women between 26 and 45 years of age and women who have never had a still birth had significantly better fetal survival (about 35-37\% and 56.8\% lower risk respectively) than their counterparts.

\section{Discussion}

This study used survival analysis techniques to study intrauterine fetal mortality. The use of this technique is appropriate and more robust than conventional descriptive techniques. The method incorporated both space and time components and used both censored and uncensored information.

The results of this study have revealed a number of facts concerning fetal mortality in Ghana. Firstly, the first trimester shows a contrary hazard trend than the second and third trimester and records most (over 50\%) of the fetal mortality. The occurrence of majority of fetal deaths in the first trimester of pregnancy, as shown in this study, is consistent with Ventura et al [6] and highlights the need for early antenatal care. Since almost half (about 47\%) of the pregnant women in Ghana do not go for antenatal care during this period [17], by encouraging early antenatal care among women in Ghana, this phenomenon could be reduced.

Secondly, the effect of bad obstetric history (BOH), represented by women ever delivered, be it live or stillbirth, or ever aborted, are shown to be significantly associated with risk of fetal mortality: This is consistent with Whitley, et al [22] study. The general lack of proper and rigorous medical examination for abortions and stillbirths in Ghana, because of the lack of technology, superstitious and cultural beliefs, societal practices and norms, etc., could easily lead to a recurrence of loss of pregnancy. The need for complete abortion care was also underscored by the high values of the chi square estimates for the log rank test for women who had aborted before. The very high risk associated with $\mathrm{BOH}$ in Ghana is unacceptable and demands an urgent education of both women and practitioners, not only to understand the seriousness of the problem, but more importantly to make it a priority issue in antenatal care.

In this study, as in MacDorman et al, [5], the effect of maternal age on fetal survival was seen. In particular, early and later aged pregnancies are shown to have significantly higher risk of fetal loss. Also, the risk of losing a pregnancy is shown to be higher in urban communities and among women who have ever been to school. This can be attributed to the stress of work and urban life in general: In Ghana, educated women are more likely to be drawn to the urban centers where the pressure and demands of work, including long working hours, 
shorter sleeping times, unmerciful transportation systems, etc, as well as other pressures and challenges of city life, is likely to put pressure on a pregnant woman and particularly, her fetus.

Data inadequacies, as in most fetal studies, are the major limitation to this study $[23,24,25]$. The undetected or unreported cases of pregnancy and fetal mortality, especially in the early stages, could lead to the underestimation of this phenomenon.

\section{Conclusion}

In this study, the incidence and pre-pregnancy risk factors for fetal mortality was studied. The survival and hazard estimates showed that the first trimester was the riskiest period of pregnancy. The Cox regression on the other hand, showed that the previous pregnancy outcomes, the age and education of the woman, as well as the place of residence were significantly associated with fetal mortality. While the results of this study could appreciably guide antenatal care, particularly in Ghana, further and regular studies are however needed to consider other preand pregnancy factors.

\section{References}

[1] March of Dimes. (2013, March). Loss and Grief. Retrieved from March of Dimes: http://www.marchofdimes.com/baby/loss.html

[2] Gold, K. J., Sen, A., \& Hayward, R. A. (2010). Marriage and Cohabitation Outcomes After Pregnancy Loss. Pediatrics, 125(5): e1202-1207.

[3] O’Riordan, M. (2013, March 29). Pregnancy Loss Associated With a Later Risk Of Atherosclerosis. Retrieved from Medscape: http://www.medscape.com/viewarticle/781681

[4] Ranthe, M. F., Andersen, E. A., Wohlfahrt, J., Bundgaard, H., Melbye, M., \& Boyd, H. A. (2013, March 27). Pregnancy loss and later risk of atherosclerotic disease. Circulation, 1775-82.

[5] MacDorman, M. F., Kirmeyer, S. E., \& Wilson, E. C. (2012, August 28). Fetal and Perinatal Mortality, United States, 2006. National Vital Statistics Reports, p. Volume 60 Number 8.

[6] Ventura, S. J., Curtin, S. C., Abma, J. C., \& Henshaw, S. K. (2012, June 20). Estimated Pregnancy Rates and Rates of Pregnancy Outcomes for the United States, 1990-2008. National Vital Statistics Reports, p. Volume 60 Number 7.

[7] Fretts, R. (2010). Stillbirth epidemiology, Risk factors, and Opportunities for stillbirth prevention. Clinical Obstetric Gynecology, 53(3): 588-96.
[8] Stillbirth Collaborative Research Network Writing Group. (2011). Association between Stillbirth and Risk factors known at Pregnancy confirmation. Journal of the American Medical Association, 306(22): 2469-79.

[9] ACOG Practice bullettin No 102. (2009). Management of Stillbirth. Obstetric and Gynecology, 113(3): 748-61.

[10] Smith, G. C. (2010). Predicting Antepartum Stillbirth. Clinical Obstetriec and Gynecology, 53(3): 597-606.

[11] Salihu, H. M. (2011). Maternal Obesity nd Stillbirth. Seminars in Perinatology, 35(6): 340-4.

[12] Bukowski, R. (2010). Stillbirth and Fetal Growth Restriction. Clinical Obstetric and Gynecology, 53(3): 673-80.

[13] Reddy, U. M., Laughon, S. K., Sun, L., Troendle, J., Willinger, M. \& Zhang, J. (2010). Prepregnancy Risk factors for Antepartum Stillbirth in the United States. Obstetrics Gynecology, 116(5): 1119-26.

[14] Ananth, C. V., \& Basso, O. (2010). Impact of Pregnancy-Induced Hypertension on Stillbirth and Neonatal Mortality. Epidemiology, 21(1): 118-23.

[15] Venners, S. A., Wang, X., Chen, C., Wang, L., Chen, D., Guang, W., Xu, X. (2004). Paternal Smoking and Pregnancy Loss: A Prospective Study Using a Biomarker of Pregnancy. Ametican Journal of Epidemiology, 159 (10): 993-1001.

[16] NCC-WCH. (2008). Antenatal Care: routine care for the healthy pregnant woman. London: RCOG Press.

[17] GSS; GHS; Macro Interntional, 2009. Ghana Maternal Health survey, Accra; Calverton, Maryland: GSS, GHS, and Macro International.

[18] Gehan, E. A. (1969). Estimating Survival Function from the Life Table, Vol 21;. Journal of Chronic Diseases , 629-644.

[19] Greenwood, M. (1926). The Natural duration of Cancer. Reports on Public Health and Medical subjects , 1-26.

[20] Peto, R., \& Peto, J. (1972). Asymtotically Efficent rank Invariant Proceedures. Journal of the Royal Statistical Society, Series A:135, 185-207.

[21] Cox, D. R. (1972). Regression Models and Life Tables. Journal of the Royal Statistical Society, 34(Series B), 187-220.

[22] Whitley, E., Doyle, P., Roman, E., \& De Stavola, B. (1999). The effect of reproductive history on future pregnancy outcomes. Human Reproduction, 14(11): 2863-7.

[23] Makelarski JA, Romitti PA, Caspers KM, Puzhankara S, McDowell BD, Piper KN. (2011). Use of active surveillance methodologies to examine over-reporting of stillbirths on fetal death certificates. Birth Defects Res (A): Clinical and Molecular Teratology 91(12):1004-10.

[24] Heuser CC, Hunn J, Varner M, Hossain S, Vered S, Silver RM. (2010). C.orrelation between stillbirth vital statistics and medical records. Obstetrics and Gynecology 116(6):1296-301. 2010.

[25] Lydon-Rochelle MT, Càrdenas V, Nelson JL, Tomashek KM, Mueller BA, Easterling TR. (2005). Validity of maternal and perinatal risk factors reported on fetal death certificates. American Journal of Public Health 95(11):1948-51. 